\title{
Community mental health teams for older people in England: Variations in ways of working
}

Citation for published version (APA):

Verbeek, H., Worden, A., Wilberforce, M., Brand, C., Tucker, S., Abendstern, M., \& Challis, D. (2018). Community mental health teams for older people in England: Variations in ways of working. International Journal of Geriatric Psychiatry, 33(3), 475-481. https://doi.org/10.1002/gps.4775

Document status and date:

Published: 01/03/2018

DOI:

10.1002/gps.4775

Document Version:

Publisher's PDF, also known as Version of record

Document license:

Taverne

Please check the document version of this publication:

- A submitted manuscript is the version of the article upon submission and before peer-review. There can be important differences between the submitted version and the official published version of record.

People interested in the research are advised to contact the author for the final version of the publication, or visit the DOI to the publisher's website.

- The final author version and the galley proof are versions of the publication after peer review.

- The final published version features the final layout of the paper including the volume, issue and page numbers.

Link to publication

\footnotetext{
General rights rights.

- You may freely distribute the URL identifying the publication in the public portal. please follow below link for the End User Agreement:

www.umlib.nl/taverne-license

Take down policy

If you believe that this document breaches copyright please contact us at:

repository@maastrichtuniversity.nl

providing details and we will investigate your claim.
}

Copyright and moral rights for the publications made accessible in the public portal are retained by the authors and/or other copyright owners and it is a condition of accessing publications that users recognise and abide by the legal requirements associated with these

- Users may download and print one copy of any publication from the public portal for the purpose of private study or research.

- You may not further distribute the material or use it for any profit-making activity or commercial gain

If the publication is distributed under the terms of Article $25 \mathrm{fa}$ of the Dutch Copyright Act, indicated by the "Taverne" license above, 


\title{
Community mental health teams for older people in England: Variations in ways of working
}

\author{
Hilde Verbeek ${ }^{1,2}$ | Angela Worden ${ }^{1}$ | Mark Wilberforce ${ }^{1}$ | Christian Brand ${ }^{1,3}$ | Sue Tucker ${ }^{1}$ | \\ Michele Abendstern ${ }^{1}$ | David Challis ${ }^{1}$
}

${ }^{1}$ Personal Social Services Research Unit, University of Manchester, UK

${ }^{2}$ CAPHRI School for Public Health and Primary Care, Department of Health Services

Research, Maastricht University,

The Netherlands

${ }^{3}$ Department of Health Services Research and Policy, London School of Hygiene and Tropical Medicine, London, UK

\section{Correspondence}

David Challis, Personal Social Services Research Unit, University of Manchester, UK. Email: d.j.challis@manchester.ac.uk

Funding information

NIHR Programme Grants for Applied Research, Grant/Award Number: RP-PG0606-1109
Objective: Integrated community mental health teams (CMHTs) are a key component of specialist old age psychiatry services internationally. However, in England, significant shifts in policy, including a focus on dementia and age inclusive services, have influenced provision. This study portrays teams in 2009 against which subsequent service provision may be compared.

Methods: A bespoke national postal survey of CMHT managers collected data on teams' structure, composition, organisation, working practices, case management, and liaison activities.

Results: A total of 376 CMHTs (88\%) responded. Teams comprised a widespread of disciplines. However, just $28 \%$ contained the full complement of professionals recommended by government policy. Over $93 \%$ of teams had a single point of access, but some GPs bypassed this, and $40 \%$ of teams did not accept direct referrals from care homes. Initial assessments were undertaken by multiple disciplines, and $71 \%$ of teams used common assessment documentation. Nevertheless, many social workers maintained both NHS and local authority records. In $92 \%$ of teams, nominated care coordinators oversaw the support provided by other team members. However, inter-agency care coordination was less prevalent. Few teams offered the range of outreach/liaison activities anticipated in the national dementia strategy.

Conclusions: Compared with previous studies, teams had grown and changed, with a clear increase in non-medical practitioners, particularly support workers. Measures to facilitate integrated care within CMHTs (eg, common access and documentation) were widespread, but integration across health and social care/primary and secondary services was less developed. Consideration of barriers to further integration, and the impact of current reforms is potentially fruitful.

\section{KEYWORDS}

community mental health teams, consultant psychiatrists, integration, older people

\section{I INTRODUCTION}

Community mental health teams (CMHTs) for older adults are internationally regarded as the exemplar first-tier specialist service for psychiatric support in later life. ${ }^{1-3}$ In England, the development of specialist community teams dates from the $1940 s,{ }^{4}$ yet the more recent history of service design is characterised by variability and constantly shifting policy priorities. Two national analyses at the turn of the century found much divergence in provision; CMHTs were fully available in less than half of areas, and there was a widespread need for more day and respite care. ${ }^{5,6}$ Moreover, this client group were not included in the national mental health strategy ${ }^{7}$ and received scant attention (and no dedicated resources) in the older people's strategy. ${ }^{8}$ The publication of Everybody's Business, a service development guide, in 2005, was thus widely welcomed. ${ }^{9}$ This identified multidisciplinary (ideally multiagency) CMHTs with streamlined referral systems and common assessment and care planning processes as the "backbone" of comprehensive services for older adults with mental health problems. However, once again, there were no new monies.

It was not until 2009, with the launch of the National Dementia Strategy, ${ }^{10}$ that real momentum for change was gained, and the last few years have seen a steady stream of initiatives designed to improve care for this client group. ${ }^{11-14}$ Initially, this new focus on dementia prompted many services to separate support for people with organic 
and functional disorders, with treatment for the latter amalgamated within CMHTs for working age adults to create "ageless" or "age inclusive" services. Indeed, by 2012, 1 in 5 Trusts had moved to ageless services or planned to do so imminently. ${ }^{15}$ A concerted effort by old age psychiatrists and other interested organisations, however, supported by new evidence that ageless services were less effective in meeting needs than specialist old age services challenged these moves. ${ }^{16}$ Age inclusiveness was pronounced counterproductive by the Mental Health Taskforce, ${ }^{17}$ and older adult CMHTs were reinstated as the preferred model.

This renewed attention has brought some important challenges into sharper focus. Not least of these are the rising number of older people with mental health problems, and the continuing policy drive to treat ever more people in the community via integrated services. ${ }^{18}$ However, the content of the latter is not clear. Definitions of integration vary (covering different disciplines, services, and agencies), and concerns have been expressed that staff in integrated teams may become deskilled, with a potential loss of specialist expertise and medical leadership. ${ }^{19,20}$ Further, there is a lack of routinely collected good quality data with which to compare services at a point in, or over, time. $^{21}$

Against this background, the paper summarises the core features of variation in the structure and organisation of CMHTs in England in 2009-the beginning of this period of change-providing a baseline against which subsequent developments in practice and emphasis can be evaluated.

\section{2 | METHOD}

A postal questionnaire was sent to the managers of all 429 CMHTs for older people in England identified in the 2008 Combined Mapping Framework ${ }^{22}$ in November 2008. Data collection closed in March 2009. The schedule was developed by the research team in collaboration with a steering group of experts in old age mental health services and was piloted with 6 teams from 3 mental health trusts (organisations delivering specialist mental health services). The content was informed by previous surveys of CMHTs and consultants in old age psychiatry ${ }^{23-25}$ and a review of the literature, ${ }^{26}$ and covered 3 main domains. Information was sought on teams' structure and composition (eg, location and staff mix); organisation and working practice, including several indicators of joint working (eg, access, assessment and care planning arrangements); and liaison and support activities. ${ }^{27-29}$ Precoded response sets were provided for most items, but free text boxes encouraged respondents to expand/clarify their answers to particular questions. As not all items were applicable to all respondents, the following figures are given as a percentage of those participants who answered each individual question.

\section{3 | FINDINGS}

Three hundred and seventy six teams returned data-an $88 \%$ response rate. This included at least 1 team from $93 \%$ of trusts. Whilst most teams saw a mixture of patients with functional and organic mental health problems, 4 teams saw only patients with dementia, and 2

\section{Key points}

- Care coordinators usually oversaw care provided by team members, but inter-agency care coordination was less prevalent

- Compared with previous work, there was a clear increase in non-medical practitioners and unqualified support workers in teams

- Relatively few teams offered the range of outreach/ liaison activities outlined in England's national dementia strategy

- Despite systems to coordinate care within teams, integrated work between health and social care and between primary and secondary care was less common

saw only patients with functional disorders. Comparison of respondents with the full sampling frame indicated no significant response bias with respect to geographical spread or selected team characteristics.

\subsection{Team structure and composition}

The majority of teams had been in operation for more than 5 years (72\%); covered an urban or mixed urban and rural catchment area (85\%); and were based in community mental health centres or alongside old age psychiatry inpatient wards (70\%). Approaching three-quarters (71\%) worked with 1 local authority (units of local government responsible for the provision of social care); $17 \%$ worked with 2; and the remainder worked with 3 or more.

Questions about team composition differentiated between "core" team members (who devoted most, if not necessarily all, of their time to the CMHT and/or had greater responsibility for its operation) and "sessional" members (who had regular but more limited input). Almost all teams had a team manager or coordinator (97\%), who was typically a nurse by profession (73\%). However, there was considerable variation in team size, with a mean of 18.1 members (standard deviation 8.8), and a range of 1 to 47 (excluding administrative staff). Of these, the vast majority were core staff (mean 16.5, standard deviation 8.0). Nevertheless, just $28.5 \%$ of teams could be seen as comprehensive containing a full complement of consultant psychiatrists, community mental health nurses, occupational therapists, psychologists, social workers, and support workers (a generic term for unregistered, assistant-grade practitioners), whilst almost a tenth (9.6\%) were unable to access any psychology input and around 1 in 20 (4.3\%) lacked occupational therapy input.

Community mental health nurses were the most frequently reported (and numerous) profession (see Table 1), while consultant psychiatrists, occupational therapists, and support workers were core members of more than four-fifths of teams. Consultant psychiatrists were also amongst the 3 disciplines most likely to provide sessional input (along with other doctors and psychologists). However, it 
TABLE 1 Core team membership

\begin{tabular}{|c|c|c|c|}
\hline \multirow{2}{*}{$\frac{\text { Member }}{\text { Team manager }}$} & \multirow{2}{*}{$\begin{array}{l}\text { Percentage of teams that contained different practitioners } \\
93.9\end{array}$} & \multicolumn{2}{|c|}{ Mean number of staff (range) } \\
\hline & & 1.2 & $(0-6)$ \\
\hline Community mental health nurse & 98.9 & 5.5 & $(0-19)$ \\
\hline Other doctor & 64.6 & 1.1 & $(0-6)$ \\
\hline Occupational therapist & 84.0 & 1.2 & $(0-4)$ \\
\hline Support worker ${ }^{a}$ & 87.0 & 2.5 & $(0-15)$ \\
\hline Other ${ }^{b}$ & 40.0 & 1.1 & (0 to 30$)$ \\
\hline
\end{tabular}

${ }^{\mathrm{a}} \mathrm{A}$ generic term for unregistered, assistant-grade practitioners.

${ }^{\mathrm{b}}$ Including dieticians, speech and language therapists, and physiotherapists.

appeared that teams were both growing in size and changing. Almost two-thirds of respondents (63\%) identified that there had been major changes to the way their team was organised in the previous 12 months (eg, in staff numbers, management structure, or team organisation).

\subsection{Organisation and working practice}

\subsection{1 | Referrals}

Teams accepted an average (mean) of 43.4 referrals in the previous calendar month, ranging from 10 to 250 (median = 36), dependent, at least in part, on team size ( $r=0.47)$. As would be expected, almost all teams (96\%) received a large proportion of their referrals from General Practitioners (GPs). Over and above this, practice varied widely. Whereas approximately an eighth of teams (12.8\%) received a large proportion of referrals from care homes, more than a third (40.4\%) did not accept referrals from this source. Likewise, less than half of teams accepted referrals from voluntary organisations and a similar proportion did not accept self-referrals.

In nearly all teams, referrals were received via a single point of access (93.3\%, Table 2), whilst day-to-day decisions about the eligibility of referrals and the allocation of cases to different team members were generally made by the team as a whole $(51.5 \%$ and $46.1 \%$, respectively) or the team manager (29.2\% and $42.6 \%$, respectively). Although four-fifths of teams (80.4\%) used formal referral eligibility criteria, around an eighth of teams lacked such criteria and a further $7 \%$ had them, but did not use them (Table 2).

\section{3 | Assessments}

Approximately a sixth of referrals were seen with a week of receipt of referral (16.6\%), and approaching two-thirds of referrals within 2 weeks (63.3\%, Table 2). Almost all referrals were seen within 1 month (94.3\%). Community mental health nurses and consultant psychiatrists were most likely to conduct initial assessments (see the first 2 columns of Table 3), and consultant psychiatrists were said to see all or most of the team's caseload at some point in over half of teams (57.6\%). However, other doctors and occupational therapists also conducted initial assessments in approximately three-quarters of teams, and where psychologists or social workers were core team members, the probability that they would undertake initial assessments increased to $61.6 \%$ and $78.6 \%$, respectively.

TABLE 2 Care process (\% teams reporting different activities)

\begin{tabular}{|c|c|}
\hline Activity & $\%$ \\
\hline \multicolumn{2}{|l|}{ Referral and assessment } \\
\hline Single access point to referral & 93.3 \\
\hline \multicolumn{2}{|l|}{ Referral or eligibility criteria } \\
\hline Used regularly & 80.4 \\
\hline Not used regularly & 7 \\
\hline Use same structured assessment documentation & 70.7 \\
\hline \multicolumn{2}{|l|}{ Time from referral to first visit } \\
\hline$<1$ week & 16.6 \\
\hline$<2$ weeks & 46.7 \\
\hline$<1$ month & 31.1 \\
\hline$>1$ month & 5.6 \\
\hline Team using electronic service user records? & 70 \\
\hline $\begin{array}{l}\text { Team and the local services team able to access each other's } \\
\text { service user records }\end{array}$ & 31.6 \\
\hline \multicolumn{2}{|l|}{ Medical input } \\
\hline All or most of team's caseload seen by consultant psychiatrist & 57.6 \\
\hline \multicolumn{2}{|l|}{ Care plan } \\
\hline $\begin{array}{l}\text { Service users having a single care plan with details of each team } \\
\text { member's input? }\end{array}$ & 86.8 \\
\hline \multicolumn{2}{|l|}{ Staff group authorising services funded by local authority } \\
\hline Community mental health nurses & 14.4 \\
\hline Consultant psychiatrists & 1.6 \\
\hline Other doctors & 0.8 \\
\hline Clinical psychologists & 0.8 \\
\hline Occupational therapists & 8.8 \\
\hline Social workers & 43.5 \\
\hline Support workers & 3.5 \\
\hline \multicolumn{2}{|l|}{ Service users routinely receiving copies of: } \\
\hline Care plan & 85.8 \\
\hline Clinical letters & 53.3 \\
\hline \multicolumn{2}{|l|}{ Case management } \\
\hline Care coordinator who coordinates care provided by the team & 92.5 \\
\hline $\begin{array}{l}\text { Care coordinator who coordinates care provided by both team and } \\
\text { other services }\end{array}$ & 59.7 \\
\hline
\end{tabular}


TABLE 3 Staff roles (\% teams reporting different staff)

\begin{tabular}{lll} 
Staff group & Conducts initial assessments (\% of teams ${ }^{\mathrm{a}}$ ) & Acts as key worker/care coordinator $\left(\%\right.$ of teams ${ }^{\mathrm{a}}$ ) \\
\hline Community mental health nurses & 99.2 & 98.7 \\
Consultant psychiatrists & 92.0 & 68.0 \\
\hline Other doctors & 76.3 & 43.2 \\
\hline Occupational therapist & 73.9 & 78.1 \\
\hline Psychologists & 47.5 & 44.3 \\
\hline Social workers & 59.7 & 61.3 \\
\hline Support workers & 3.5 & 9.9 \\
\hline Other & 6.7 & 5.3 \\
\hline
\end{tabular}

${ }^{a}$ Figures relate to all teams. Note, as above, some teams will not have contained particular professions.

Nearly all assessments (93.3\%) were conducted in patients' homes. However, 187 teams indicated that practice varied by professional group. Of these, the majority $(88.7 \%)$ said that nurses were particularly likely to conduct assessments in patients' homes, whilst just $8 \%$ said psychologists were particularly likely to do so. All staff groups used the same structured assessment documentation in just over two-thirds of teams (70.7\%).

\subsection{Case management, care planning, and case closure.}

In the vast majority of teams (92.5\%), all or most patients had a named care coordinator who oversaw the care provided by the team, whilst a similarly high percentage $(86.8 \%)$ said that all patients had a single care plan which contained the details of each member's input as well as support from other services, such as day or home care. By contrast, considerably fewer teams (59.7\%) said a named care coordinator oversaw the input provided by both the CMHT and other services/agencies for all or most patients, and only a third of teams (31.6\%) were able to access local social services team records for their patients (Table 2).

Community mental health nurses were most likely to act as care coordinators, followed by occupational therapists, consultant psychiatrists, and social workers (see the right-hand column of Table 3). However, in teams where social workers were core team members, the likelihood that they would take on a care coordinator role increased to $81.1 \%$. Not surprisingly, within teams, social workers were most likely to authorise services funded by the local authority $(43.5 \%$ of teams), although in a significant minority of teams (14.4\%), community mental health nurses also had this authority. Lead responsibility for closing cases was taken by individual team members in $33.1 \%$ of teams; the team as a whole in $37.1 \%$; and the team manager in $15.2 \%$.

\subsection{Liaison and support activity}

Nearly all teams (96\%) provided support for staff in mainstream settings over and above their response to case-by-case referrals (Table 4). Much of this appeared to be informal (eg, the provision of telephone advice). However, $92 \%$ undertook some type of formal outreach activity in at least 1 mainstream setting, with nearly threequarters of these (73.4\%) having formal arrangements with care homes, and approaching half (47.1\%) providing support for day centres.

Education and training were the most common form of support (provided by $75.9 \%$ of teams), whilst approaching two-thirds of teams (63.2\%) had dedicated link workers (individual team members nominated to liaise with and act as a first point of contact for staff) in particular settings. By contrast, far fewer teams ran case finding or screening programmes, or open clinics (regular scheduled visits to see/discuss people causing concern).

Community mental health nurses (CMHNs) undertook outreach work in $96.3 \%$ of teams. However, occupational therapist and consultant psychiatrists also had outreach roles in $64.2 \%$ and $60.1 \%$ of teams, respectively. ${ }^{25}$

\section{4 | DISCUSSION}

This paper provides a unique picture of the configuration of CMHTs for older people in England at the start of a period of intense interest in the needs of older people with mental health problems, with a focus

TABLE 4 Liaison and support (\% teams reporting different activities) ${ }^{a}$

\begin{tabular}{|c|c|c|c|c|c|}
\hline \multirow[b]{2}{*}{ Setting } & \multicolumn{5}{|c|}{ Form of support } \\
\hline & Open clinic & Link worker & Case finding and/or screening & Education or training & Other general liaison work \\
\hline GP surgeries/primary care & 3.1 & 23.8 & 5.3 & 17.5 & 40.4 \\
\hline Day centres & 4.4 & 21.6 & 7.5 & 35.7 & 51.3 \\
\hline Social service teams & 1.1 & 16.3 & 12.5 & 25.8 & 57.1 \\
\hline
\end{tabular}

${ }^{a}$ Figures refer to the $96 \%$ of teams that said they undertook liaison work. 
on team structure and composition, organisation and working practice, and liaison and support activities. As such, it provides an important benchmark against which subsequent service provision (or provision in other countries) can be compared and gives some indication of the challenges they faced. The discussion explores some of the key issues raised by the findings, with particular consideration of the implications for the drive towards greater integration, and the role of consultant psychiatrists.

\section{1 | Team structure and composition}

Compared with a previous survey of old age psychiatrists in $2004,{ }^{25}$ this study suggests that the profile of CMHTs was becoming more multidisciplinary, with an increase in the representation of all 6 key disciplines advocated by policy guidance $\mathrm{e}^{8,9,18}$ and a trend towards core as opposed to sessional team membership, in which staff may have divided loyalties between services and roles. Particular growth was seen in the proportion of teams that contained occupational therapists and psychologists as core staff (up from just under two-thirds to $84.0 \%$ and a third to $50.3 \%$, respectively). The staff mix and roles appear not dissimilar to those described in service statements in Australia. ${ }^{30} \mathrm{How}$ ever, the most striking change was in the number of teams containing assistant-grade support workers (87.0\%), considering that just 4 years previously, a quarter of teams had no access to them at all. Recent qualitative work has shed light on the wide variety of tasks that support workers undertake in CMHTs, and the supervisory and training challenges this brings. ${ }^{31}$ Nevertheless, still less than a third of CMHTs had all 6 key disciplines as core team members; almost a third had no core team social workers; and a tenth could not access any psychology input. Further, the findings reflect a global trend in healthcare provision towards an increase in the proportion of unqualified as opposed to qualified staff, ${ }^{32-34}$ and a relative increase in the presence of nonmedical as opposed to medically trained personnel. For comparison, it is noteworthy that Old Age Psychiatry as a specialty has been described as largely an Anglo-Saxon phenomenon and in Europe services are highly variable. ${ }^{35,36}$ One report suggested that only the Netherlands, Switzerland, and the UK possessed a significant level of specialist provision. ${ }^{37}$

\subsection{Organisation and working practice}

The study found that almost all CMHTs had a single point of access (a measure expected to facilitate integrated care). However, free text comments suggested that practice was more "messy" than this suggested. For example, some respondents stated that particular GPs "deliberately" sent referrals to preferred consultants with a view to bypassing the system, whilst others said that primary care practitioners lacked knowledge and understanding of the referral process. The finding that around an eighth of teams lacked formal referral criteria may not have helped in this respect, albeit the development of such criteria per se is not of course sufficient to ensure their regular use.

The large proportion of referrals that came via primary care was not a surprise, whilst compared with a study in $2000,{ }^{23}$ the proportion of teams that accepted referrals from friends, relatives and neighbours appeared to have risen considerably (from approximately a quarter to half). The proportion of teams that accepted referrals from care homes had also increased. Nevertheless, despite the high number of care home residents with complex mental health problems, ${ }^{9,38} 40 \%$ of teams still did not accept direct referrals from this source. In many cases, this was because respondents required GPs or other physicians to rule out any physical explanation for residents' presenting symptoms prior to their referral. Whether the benefits of such screening outweigh the potential delay in mental health assessment is not known. Moreover, ease of access to health services is itself an indicator of care quality, ${ }^{39}$ and past research found fears that open access might release a flood of inappropriate referrals were not substantiated. $^{40-42}$

Writing about a series of visits to high profile old age psychiatry services in the UK over 20 years ago, Dening ${ }^{43}$ found the most contentious issue concerned who should undertake initial assessments. The majority of services he visited argued that all referrals should initially be seen by medical staff, but opponents of this view felt that with training assessments could be undertaken all CMHT members and that this was more efficient and cost-effective. Further, a series of contemporary studies appeared to suggest that not all initial assessment needed to be performed by a doctor in terms of the accuracy of diagnosis. ${ }^{44-46}$ The current study suggests that by 2008 it was common practice for multiple professionals to undertake such assessments, perhaps at least partly in response to the relative increase in the availability of non-medical as opposed to medical time. However, little is known about the relative outcomes of patients assessed (or managed) by non-medical as opposed to medical personnel, or indeed of teams in which all or most patients are seen by a consultant, as opposed to only some, and the finding that over half of teams said all or most patients were still seen by a consultant at some point is notable, not least for its resource implications.

Whilst common assessment and care planning processes are seen to facilitate effective information sharing and integrated care, ${ }^{9,18}$ this survey found that in almost a third of teams, staff used different assessment documents. Free text comments suggested that doctors, in particular, often maintained separate records, whilst many respondents reported that social workers were required to complete both the team's paperwork and separate local authority reports, duplicating rather than streamlining work. Similarly, although there had been a considerable increase in the proportion of teams in which all or most patients had a single care coordinator since 2004 (from $84.5 \%{ }^{25}$ to 99.7\%), still more than 1 in 8 teams did not allocate a care coordinator to oversee the inter-agency care of any of its patients, suggesting case management was by no means fully implemented. Cross agency informing sharing was similarly at best, limited.

Despite the introduction of certain structures to deliver integrated care within teams, therefore, less progress appeared to have been made on measures that required a higher degree of trust and cooperation at an agency level. This begs the question as to whether this matters for patient care. An observational study comparing patients supported by integrated and non-integrated CMHTs identified that integration was associated with the delivery of more intensive and wide-ranging community support, but no evidence could be found that patient outcomes were otherwise improved. ${ }^{47} \mathrm{~A}$ robust evidence base 
to support efforts towards integrated care remains elusive. Nevertheless, it is cited as a policy goal and activity across jurisdictions. ${ }^{48,49}$

\section{3 | Liaison and support activities}

Given the very high number of older people with mental health problems in England with more than 680000 people with dementia alone in $2013,{ }^{50}$ it clearly is not possible for specialist mental health services to see them all. Moreover, this should not be necessary, for with support from specialist personnel, primary care and general hospital staff appear able to diagnose and manage the majority of clients. ${ }^{8,51,52}$ The National Dementia Strategy ${ }^{10}$ advised an extension of the CMHT role to support care homes, and the present study suggests this is needed, for whilst the majority of teams provided support to such staff, relatively few offered the full range of formal structures arguably expected, including link workers and case finding activities. Furthermore, the overall pattern of support provided to staff in mainstream settings (including primary care) was patchy, and many teams said they lacked the time and resources to provide the assistance required. Other jurisdictions have similarly demonstrated and advised the development of such links. ${ }^{35,48,49,53}$

\section{4 | Methodological issues}

Whilst the survey's high response rate (>85\%) gives confidence in the representativeness of the findings, the results express the views of just 1 stakeholder group (team managers) and other team members may have had different perspectives. Further, although the paper details how teams worked, no attempt was made to assess the sufficiency or quality of services. In addition, particularly in larger units, it appeared there was some variation in what exactly constituted "a team". Thus, although the vast majority of respondents described their CMHT as a single, discrete entity, a small number of teams $(<5 \%)$ appeared to have a broader remit than would be expected (including staff usually employed in separate memory or home treatment services). However, it is possible that these responses were from service (as opposed to team) managers and related to multiple teams.

\section{5 | CONCLUSIONS}

This survey indicates that although many CMHTs had put in place many of the measures designed to facilitate more integrated care within teams, less progress had been made in the integration of care between agencies (health and social care) or between primary and secondary services, despite the obvious importance of joint working across these interfaces. Some features of traditional "silo working" appear still present in some teams, such as a lack of standardised assessment documentation across all professions. Notable in comparison to earlier work was the growth in number of unqualified support-grade staff. This survey acts as a baseline against which to examine developments, as teams continue to be subject to varied policy and resource pressures. ${ }^{54}$ There remains an urgent need to continue to monitor the way in which services develop and the impact of these changes.

\section{ACKNOWLEDGEMENTS}

We are grateful to all the CMHT staff that completed this survey.

This paper outlines independent research commissioned by the National Institute for Health Research (NIHR) under its Programme Grants for Applied Research (grant number RP-PG-0606-1109). The views and opinions expressed by authors in this publication are those of the authors and do not necessarily reflect those of the NHS, the NIHR or the Department of Health.

The Niels Stensen foundation provided funding for HVs work at the PSSRU in Manchester, UK.

\section{ORCID}

David Challis 1 http://orcid.org/0000-0002-6464-2286

\section{REFERENCES}

1. Wertheimer J. Psychiatry of the elderly: a consensus statement. Int J Geriatr Psychiatry. 1997;12(4):432-435.

2. World Health Organisation. Dementia: A Public Health Priority. Geneva: WHO Press; 2012.

3. World Health Organization, World Psychiatric Association. Organisation of care in psychiatry of the elderly: a technical consensus statement. Geneva: WHO Press; 1997.

4. Hilton C. The origins of old age psychiatry in Britain in the 1940s. Hist Psychiatry. 2005;16(63 Pt 3):267-289.

5. Audit Commission. Forget Me Not: Mental Health Services for Older People. London: Audit Commission; 2000.

6. Audit Commission. Forget Me Not 2002: Developing Mental Health Services for Older People in England. London: Audit Commission; 2002.

7. Department of Health. National Service Framework for Mental Health. Modern Standards and Service Models. London: Department of Health; 1999.

8. Department of Health. National Service Framework for Older People. London: Department of Health; 2001.

9. Department of Health, Care Services Improvement Partnership. Everybody's Business. Integrated Mental Health Services for Older Adults: A Service Development Guide. London: Department of Health; 2005.

10. Department of Health. Living Well with Dementia: A National Dementia Strategy. London: Department of Health; 2009.

11. Department of Health. Prime Minister's Challenge on Dementia. London: Department of Health; 2012.

12. Department of Health. Prime Minister's Challenge on Dementia 2020 London: Department of Health; 2015.

13. National Institute for Clinical Excellence. Dementia: support in health and social care. Quality Standard. 2010;1. https://www.nice.org.uk/ guidance/QS1

14. National Institute for Clinical Excellence. 2015. Older people: independence and mental wellbeing. NICE guideline NG32. https://www.nice. org.uk/guidance/ng32

15. Warner J. Wither old age psychiatry? Int Psychogeriatr. 2014;26(7) 1055-1058.

16. Abdul-Hamid WK, Lewis-Cole K, Holloway F, Silverman AM. Comparison of how old age psychiatry and general adult psychiatry services meet the needs of elderly people with functional mental illness: cross-sectional survey. Br J Psychiatry. 2015;207(5):440-443.

17. Mental Health Taskforce to the NHS in England (2016). Five year forward view for mental health

18. Joint Commissioning Panel for Mental Health. 2013. Guidance for commissioners of older people's mental health services.

19. McCormack $\mathrm{H}$. Old age psychiatry and integration: what does it mean and which road do we choose? Old Age Psychiatrist. 2014;60. http:// 
www.rcpsych.ac.uk/workinpsychiatry/faculties/oldagepsychiatry/newsletters/enewsletterseptember2014.aspx\#editorial

20. Morris C. Medical leadership: it's not an option! Old Age Psychiatrist. 2014;59. http://www.rcpsych.ac.uk/workinpsychiatry/faculties/ oldagepsychiatry/newsletters/enewslettermay2014.aspx

21. Healthcare Commission. Equality in Later Life: A National Study of Older People's Mental Health Services. London: Healthcare Commission; 2009.

22. National Equalities in Mental Health. 2009. Finance and service mapping. http://www.nmhdu.org.uk/our-work/mhep/later-life/ everybodysbusiness/finance-and-service-mapping/

23. Challis D, Reilly S, Hughes J, Burns, A, Gilchrist H, Wilson K. Policy, organisation and practice of specialist old age psychiatry in England. Int J Geriatr Psych. (2002);17(11):1018-1026.

24. Onyett S, Heppleston T, Bushnell D. A national survey of community mental health teams: team structure and process. J Ment Health. 1994;3(2):175-194.

25. Tucker S, Baldwin R, Hughes J, et al. Old age mental health services in England: implementing the National Service Framework for older people. Int J Geriatr Psych. 2007;22(3):211-217.

26. Abendstern M, Harrington V, Brand C, Tucker S, Wilberforce M, Challis D. Variations in structures, processes and outcomes of community mental health teams for older people: a systematic review of the literature. Aging Ment Health. (2012);16(7):861-873.

27. Challis D, Tucker S, Wilberforce $M$, et al. National trends and local delivery in old age mental health services: towards an evidence base. A mixed-methodology study of the balance of care approach, community mental health teams and specialist mental health outreach to care homes. Programme Grants Appl Res. 2014;2(4):

28. Wilberforce M, Harrington V, Brand C, Tucker S, Abendstern M, Challis D. Towards integrated community mental health teams for older people in England: progress and new insights. Int J Geriatr Psych. (2011);26(3):221-228.

29. Wilberforce M, Tucker S, Abendstern M, Brand C, Giebel C, Challis D. Membership and management: Structures of inter-professional working in community mental health teams for older people in England. Int Psychogeriatr. (2013);25(9):1485-1492.

30. SA Health (South Australia Health). Older persons mental health services. South Australia Health: Adelaide; 2017. http://www.sahealth.sa.gov. $\mathrm{au} / \mathrm{wps} / \mathrm{wcm} / \mathrm{connect} /$ public+content/sa+health+internet/health+services/mental+health+services/older+persons+mental+health+services (accessed 11 July 2017).

31. Wilberforce M, Abendstern M, Tucker S, Ahmed S, Jasper R, Challis D. Support workers in community mental health teams for older people: roles, boundaries, supervision and training. J Adv Nurs. (2017);73(7): 1657-1666.

32. Duffield C, Twigg D, Pugh J, Evans G, Dimitrelis S, Roche M A. The use of unregulated staff: time for regulation? Policy Polit Nurs Pract. (2014);15(1-2):42-48.

33. Frenk J, Chen L, Bhutta ZA, et al. Health professionals for a new century: transforming education to strengthen health systems in an interdependent world. Lancet. 2010;376(9756):1923-1958.

34. Fulton BD, Scheffler RM, Sparkes SP, Auh EY, Vujicic M, Soucat A. Health workforce skill mix and task shifting in low income countries: a review of recent evidence. Hum Resour Health. 2011;9(1):1-11.

35. Fernandes L, Mateos R, Engedal K, et al., on behalf of the President Forum Working Group of the International Psychogeriatric Association. The state of psychogeriatrics in Europe: challenges and opportunities in six European countries. Int Psychogeriatr. 2015;27:1243-1246.

36. UEMS (Union Europeene des Medicina Specialistes). (2013). Old age psychiatry in Europe: Available at: http://uemspsychiatry.org/wp-content/uploads/ 2014/03/2013Oct-Old-Age-Psych-in-Europe.pdf accessed 11 July 2017
37. Draper, B., \& Low, L. (2004) What is the effectiveness of old-age mental health services? Copenhagen, WHO Regional Office for Europe (Health evidence Network Report). http://www.euro.who.int/_data/ assets/pdf_file/0008/74690/E83685.pdf?ua=1, accessed 11 July 2017

38. Lievesley N, Crosby G, Bowman C. The Changing Role of Care Homes. London: Centre for Policy on Ageing; 2011.

39. National Audit Office (2016). Mental health services: preparations for improving access.

40. MacDonald A, Goddard C, Poynton A. Impact of 'open access' to specialist services: the case of community psychogeriatrics. Int J Geriatr Psychiatry. 1994;9:709-714.

41. Gupta K, Coupland L, Fottrell E. A two-year review of an 'open access' multidisciplinary community psychiatric service for the elderly. Int J Geriatr Psychiatry. 1996;11:795-799.

42. Philpot M, Banerjee S. Mental Health Services for Older People in London. In: Johnson S, Ramsay R, Thornicroft G, Brooks L, Lelliott P, Peck E, et al., eds. London's Mental Health. The Report to the King's Fund London Commission. London: King's Fund Publishing; 1997.

43. Dening T. Community psychiatry of old age: a UK perspective. Int $J$ Geriatr Psych. 1992;7(10):757-766.

44. Coles RJ, Von Abendorff R, Herzberg JL. The impact of a new community mental health team on an inner city psychogeriatric service. Int $J$ Geriatr Psych. 1991;6(1):31-39.

45. Collighan G, Macdonald A, Herzberg J, Philpot M, Lindesay J. An evaluation of the multidisciplinary approach to psychiatric diagnosis in elderly people. BMJ. 1993;306(6881):821-824.

46. Seymour J, Saunders P, Wattis JP, Daly L. Evaluation of early dementia by a trained nurse. Int J Geriatr Psych. 1994;9(1):37-42.

47. Wilberforce M, Tucker S, Brand C, Abendstern M, Jasper R, Challis D. Is integrated care associated with service costs and admission rates to institutional settings? An observational study of community mental health teams for older people in England. Int J Geriatr Psychiatry. 2016;31(11):1208-1216.

48. NSW DH (New South Wales Department of Health). NSW Service Plan for Specialist Mental Health Services for Older People (SMHSOP) 200515. Sydney, Australia: NSW Department of Health; 2006.

49. South Australia Health. Health Policy for Older People 2010-16. Policy Guideline, Government of South Australia: Adelaide; 2009.

50. Prince M, Knapp M, Guerchet M, et al. Dementia UK: The Second Edition. London: AlzheimerOs Society; 2014.

51. Koch T, lliffe S. Dementia diagnosis and management: a narrative review of changing practice. Br J Gen Pract. 2011;61(589):e513-e525.

52. Royal College of Psychiatrists. Raising the Standard: Specialist Services for Older People with Mental Illness. Report of the Faculty of Old Age Psychiatry. London: Royal College of Psychiatrists; 2006.

53. Draper B, Meares S, McIntosh H. A psychogeriatric outreach service to nursing homes in Sydney. Aust J Ageing. 1998;17:184-186.

54. Draper B, Anderson D. The baby boomers are nearly here-but do we have sufficient workforce in old age psychiatry? Int Psychogeriatr. 2010;22(6):947-949.

How to cite this article: Verbeek $\mathrm{H}$, Worden A, Wilberforce $\mathrm{M}$, et al. Community mental health teams for older people in England: Variations in ways of working. Int J Geriatr Psychiatry. 2018;33:475-481. https://doi.org/10.1002/gps.4775 